\title{
Diet and effects of diet management on quality of life and symptoms in patients with irritable bowel syndrome
}

\author{
HEGE ØSTGAARD ${ }^{1,2}$, TRYGVE HAUSKEN ${ }^{2}$, DORIS GUNDERSEN ${ }^{3}$ and MAGDY EL-SALHY ${ }^{1,2}$ \\ ${ }^{1}$ Section for Gastroenterology, Department of Medicine, Stord Helse-Fonna Hospital, Stord; ${ }^{2}$ Section for Gastroenterology, \\ Institute of Medicine, Bergen University, Bergen; ${ }^{3}$ Department of Research, Helse-Fonna, Haugesund, Norway
}

Received July 28, 2011; Accepted October 19, 2011

DOI: $10.3892 / \mathrm{mmr} .2012 .843$

\begin{abstract}
The present study investigated the diet and quality of life of irritable bowel syndrome (IBS) patients in comparison to the background population. Furthermore, it studied the effects of guidance on diet management on changes in food intake, quality of life and symptoms. A total of 35 healthy controls, 36 IBS patients and 43 IBS patients who had received guidance on diet management 2 years earlier were included. The controls and patients were asked to complete an FFQ questionnaire, an SF-NDI questionnaire, an IBS-QoL questionnaire and a Birmingham IBS symptom score questionnaire. There were no statistical differences in the intake of calories, carbohydrates, proteins and fat between the controls and IBS patients, with or without guidance on diet management. IBS patients made a conscious choice to avoid certain food items, some of which belong to fermentable oligosaccharides, disaccharides, monosacharides and polyols (FODMAPs). They had a higher consumption, however, of other food items that are rich in FODMAPs. They also avoided other food sources which are crucial for their health. Two years after receiving guidance on diet management, IBS patients had a different diet profile. They avoided all FODMAP-rich food, consumed more food with probiotic supplements and did not avoid food sources that were crucial to their health. In addition, they had improved quality of life and reduced symptoms. Although at first sight the diet of IBS patients did not differ from that of the background population, detailed examination showed avoidance of certain food items. Guidance on the management of diet improved their choice of a healthier diet, improved quality of life and reduced IBS symptoms.
\end{abstract}

Correspondence to: Professor Magdy El-Salhy, Section for Gastroenterology, Department of Medicine, Stord Helse-Fonna Hospital, Box 4000, 5409 Stord, Norway

E-mail: magdy.el-salhy@helse-fonna.no

Key words: diet, irritable bowel syndrome, quality of life, probiotics, symptoms

\section{Introduction}

Irritable bowel syndrome (IBS) is a chronic gastrointestinal disorder in absence of any structural, physiological or biochemical abnormalities in the gastrointestinal tract (1). The condition is classified as a functional disorder for which the diagnosis is based on the presentation of symptoms. These symptoms are abdominal discomfort or pain, bloating and abdominal distension, and changes in bowel habit between diarrhoea and constipation (1). The degree of symptoms varies in different patients from tolerable to severe, where the experience of pain may vary from a nagging, colicky, sharp or dull feeling of pain. Also, the time pattern and discomfort varies immensely from patient to patient (2-14). Some complain of daily symptoms, while others report intermittent pain at intervals of weeks/months. The supportive symptoms mentioned above may also be used to subclassify IBS patients into three subtypes: diarrhoea-predominant (IBS-D), constipationpredominant (IBS-C) and alternating constipation/diarrhea (IBS-M) (2-4).

The estimated prevalence of IBS varies from 12 to $30 \%$; this large variation is explained by the use of different definitions in different studies (15). A cross-sectional population-based survey conducted in Oppland and Hedmark County in Norway using recent diagnostic criteria estimated the prevalence to affect $8.1 \%$ of the Norwegian population (16). There is a female predominance, with as many as twice the number of females as males affected. Patients with IBS have been found to have a considerable reduction in quality of life $(17,18)$. IBS reduces quality of life to the same degree of impairment as major chronic diseases, such as congestive heart failure, hepatic cirrhosis, renal insufficiency and diabetes $(17,19,20)$.

IBS is the most common gut disorder in primary healthcare, gastrointestinal clinics and in the general population, and constitutes one of the largest diagnostic groups in the gastroenterological setting $(13,21)$. IBS patients impose a substantial financial burden on society (22). Annual direct costs including the number of medical consultations and diagnostic tests (excluding prescription and over-the-counter drug costs) in the treatment of IBS is estimated to be between $\$ 1.7$ and 10 billion in the US (22). On average, IBS patients miss 13.4 days of work and school per year $(17,23)$. IBS patients have a high percentage of losing a job, quitting work or turning down a promotion, and work fewer hours as a result of their condition 
(24). The annual indirect costs in the US are estimated at up to $\$ 20$ billion (25).

Most patients with IBS believe diet plays a significant role in their symptoms and $63 \%$ are interested in knowing what food to avoid $(26,27)$. More than $60 \%$ of IBS patients report worsening of symptoms following food ingestion; $28 \%$ within 15 min of eating and 93\% within $3 \mathrm{~h}$ (28). Numerous IBS patients report problems with specific foods, most commonly implicating milk and milk products, wheat products, caffeine, certain meat, cabbage, onion, peas/beans, hot spices and fried food as the offending foods $(28,29)$.

One would expect, therefore, that IBS patients would be selective in their choice of food. However, dietary surveys among IBS patients in the community failed to detect any differences in dietary composition between IBS patients and community controls (30-32).

The present study was undertaken to investigate the diet and quality of life of IBS patients in comparison to the background population. Furthermore, it aimed at studying the effects of guidance on diet management, in regards to changes in food intake, quality of life and symptoms.

\section{Materials and methods}

Patients and healthy subjects. Patients were recruited from those who were referred to the Gastroenterology Section, Stord Helse-Fonna Hospital (unguided) and from those who received dietary guidance 2 years earlier (guided). Patients between 18 and 65 years of age who satisfied Rome III criteria for the diagnosis of IBS were considered for inclusion in the study. Those with organic gastrointestinal disease, clinically significant systemic diseases and pregnant or lactating women were excluded. Patients who had undergone any abdominal surgery, with the exception of appendectomy, Caesarean and hysterectomy, were also excluded. Healthy volunteers without any gastrointestinal complains and without any of the exclusion criteria were recruited as controls by local announcement to students at the University of Bergen and hospital employees. The study was performed in accordance with the Declaration of Helsinki and was approved by the local Committee for Medical Research Ethics. All patients provided written consent.

Study design. Four questionnaires were sent by mail to both patients and controls during October 2010 with a following reminder sent mid-December 2010. These questionnaires were the MoBa Food Frequency Questionnaire (MoBa FFQ), the Short-Form Nepean Dyspepsia Index (SF-NDI) quality of life questionnaire, the Irritable Bowel Syndrome Quality Of Life (IBS-QOL) and Birmingham IBS Symptom scores. The subjects were asked to answer the questionnaires and return them by mail.

Guidance on diet management. Guidance on diet management was provided 2 years prior to the study. The patients were asked to keep a diary where they recorded the time of eating/ drinking, and the types of food and drinks they ingested daily. Furthermore, they reported the occurrence of pain, abdominal distention, stool frequency and consistency. This was performed for at least a month. Pain and abdominal disten-
Table I. General food advice provided to IBS patients.

\begin{tabular}{ll}
\hline Food allowed & \multicolumn{1}{c}{ Food advised to avoid } \\
\hline Spelt and spelt products & Flour \\
Meat & Pasta \\
Fish & Onion \\
Chicken & Garlic \\
Fat and oils & Paprika \\
Rice & Cabbage and rutabaga \\
Potatoes & Carbonated beverages (soda) \\
Carrot & Light products (food containing \\
Apple and pear (peeled) & artificial sweeteners) \\
Citrus & Banana \\
Tomato & Beans \\
Milk & Peas \\
Coffee, tea & \\
Chocolate & \\
Alcohol & \\
Probiotic-containing foods &
\end{tabular}

tion were graded as light, moderate or severe. Two sessions with a nurse were scheduled for $\sim 1 \mathrm{~h}$ each, where information regarding the disease and the role of diet were emphasized and a review of the diary was performed together with the patient. This information was provided orally using charts and illustrative drawings. Diet instructions were focused on avoiding poorly absorbed, highly fermentable short-chain carbohydrates and sugar alcohols, the so-called fermentable oligosaccharides, disaccharides, monosaccharides and polyols (FODMAPs), regular meals and healthy eating habits (Table I). Furthermore, fiber-poor diet and trials with fat, protein, carbohydrates rich/poor diet were tried. Together with the patient, the nurse designed a suitable diet for the patient. The intention with this change of diet was to reduce the amounts of intestinal gas produced, which causes abdominal pain/discomfort and to reduce/increase the release of gastrointestinal hormones.

MoBa FFQ. The FFQ is a common dietary assessment tool used in large epidemiological studies. The self-administered FFQ asks participants to report the frequency of consumption and portion size of line items over a defined period of time. Each line item is defined by a series of foods or beverages. Additional questions on food purchasing and preparation methods enable the analysis software to further refine nutrient calculations. Although FFQs are not considered appropriate for estimating true nutrient intake at the individual level, they may be used in epidemiological studies to rank individuals along the distribution of intake, so that individuals with low intakes may be separated from those with high intakes (33). The MoBa FFQ used in this study was developed and validated by the Norwegian Institute of Public Health in Oslo, Norway (34). The MoBa FFQ is a semi-quantitative questionnaire that asks about the intake of 225 food items grouped according to the Norwegian meal pattern and is designed to capture the participant's dietary habits the previous 12 months, including any oral supplements. Data analysis provides information concerning 
Table II. Daily intake of macronutrients and alcohol in controls, unguided and guided IBS patients (means \pm SEM).

\begin{tabular}{lccc}
\hline & Controls & Unguided & Guided \\
\hline Energy (kcal) & $2,338.7 \pm 143.6$ & $2,102.9 \pm 120.0$ & $2,243.2 \pm 123.8$ \\
Carbohydrates (g) & & & $278.4 \pm 19.6$ \\
Total & $287.2 \pm 19.1$ & $257.2 \pm 18.2$ & $124.9 \pm 8.1$ \\
Starch & $139.5 \pm 11.8$ & $129.9 \pm 10.9$ & $31.5 \pm 2.1$ \\
Fiber & $32.5 \pm 2.2$ & $30.0 \pm 2.5$ & $91.2 \pm 4.2$ \\
Protein & $94.4 \pm 5.8$ & $81.3 \pm 3.8$ & $82.9 \pm 5.3$ \\
Fats (g) & & & $30.0 \pm 1.7$ \\
Total & $86.4 \pm 5.5$ & $81.2 \pm 4.7$ & $296.7 \pm 16.7$ \\
Saturated & $32.4 \pm 2.3$ & $28.9 \pm 1.7$ & $1.7 \pm 0.1$ \\
Cholesterol & $267.8 \pm 17.0$ & $261.2 \pm 12.3$ & $28.3 \pm 2.2$ \\
Trans & $2.0 \pm 0.2$ & $1.8 \pm 0.2$ & $16.8 \pm 1.5$ \\
Mono-unsaturated & $29.9 \pm 2.1$ & $27.1 \pm 1.7$ & $53.9 \pm 5.7$ \\
Polyunsaturated & $15.7 \pm 1.1$ & $17.2 \pm 1.4$ & $2.3 \pm 0.4^{\mathrm{b}, \mathrm{d}}$ \\
Sugar (g) & $51.3 \pm 6.3$ & $48.1 \pm 5.5$ & $1.9 \pm 0.4^{\mathrm{a}, \mathrm{c}}$ \\
Alcohol (ml) & $4.7 \pm 0.7$ & & \\
\hline
\end{tabular}

${ }^{\mathrm{a}}$ Controls vs. unguided IBS patients. ${ }^{\mathrm{b}}$ Controls vs. guided IBS patients. ${ }^{\mathrm{c}} \mathrm{P}<0.001 ;{ }^{\mathrm{d}} \mathrm{P}<0.01$.

the intake of energy, water, macronutrients and micronutrients, minerals and alcohol in addition to 100 specific food groups and items. It also gives information about meal patterns.

$S F-N D I$. The SF-NDI was primarily constructed and validated in patients with functional dyspepsia (35). Later, a Norwegian translation of the form was validated and proved to perform well also in patients with subjective food hypersensitivity, most of them satisfying the Rome II criteria for IBS (36). The form is a 10-item questionnaire examining the effect of dyspepsia on domains of health in patients, i.e., tension/anxiety, interference with daily activities, disruption to regular eating/drinking, knowledge towards/control over disease symptoms and interference with work/study, with each subscale containing two items. Each item is measured by a 5-point Likert scale ranging from 1 (not at all or not applicable), 2 (a little), 3 (moderately), 4 (quite a lot) to 5 (extremely). Individual items in each subscale are aggregated to obtain a score range from 10 [lowest Health Related Quality of Life (HRQoL) score] to 50 (highest HRQoL score) as per the developers' original calculation formula. High scores indicate worse functioning or symptoms.

$I B S-Q O L$. The IBS-QOL is a 34-item IBS-specific quality of life document concerning physical and psychosocial functioning as a result of IBS (37). This questionnaire includes a 5-point Likert response scale: not at all, slightly, moderately, quite a lot and extremely. IBS-QOL consist of 8 domains: dysphoria, interference with activity, body image, health worry, food avoidance, social reaction, sexual function and impact on relations. The IBS-QOL has been validated in IBS patients (38).

Birmingham IBS symptom questionnaire. The Birmingham IBS symptom score questionnaire is a disease-specific score to measure the symptoms of patients with IBS. It has been developed to be suitable for self-completion and has been found to be acceptable to patients. Its dimensions have good reliability, external validity and sensitivity (39). The questionnaire comprises 11 questions based on the frequency of IBS-related symptoms. Each question has a standard response scale with symptoms all being measured on a 5-point Likert scale ranging from 0 (none of the time) to 5 (all of the time). There are three underlying dimensions: pain (3 items), diarrhea (5 items) and constipation (3 items) (39).

Statistical analysis. Comparisons between the three groups, controls, unguided IBS and guided IBS patients, were performed with Kruskal-Wallis non-parametric ANOVA test and Dunn's test as a post-test. To compare between the groups of unguided IBS and guided IBS patients, a Mann-Whitney non-parametric test was used. P-values $<0.05$ were considered to be statistically significant.

\section{Results}

Patients and healthy subjects. A total of 42 controls, 63 unguided IBS patients and 70 guided IBS patients were enrolled in the study. A total of 79 IBS patients replied and signed a written consent form. Seven controls did not return the questionnaires. Eight letters were returned by post as the patients had moved to a new address, and we were unable to trace them. Ten patients returned the questionnaires unanswered and did not give their consent to participate in the study. These patients were 6 unguided IBS and 4 guided IBS patients. A total of 36 patients did not reply or return the questionnaire. Thus, 35 controls, 36 unguided IBS patients and 43 guided IBS patients satisfactorily completed the study. The mean age in controls, unguided IBS patients and guided IBS patients was 31 (range 20-54), 38 (range 19-61) and 40 (range 20-63) years, respectively. There was no statistical difference between the mean ages in the three groups. The percentage of males in the unguided IBS patients, guided IBS patients and controls was 19, 12 and 14\%, respectively. 
Table III. Meal pattern per week in controls, unguided and guided IBS patients (means \pm SEM).

\begin{tabular}{lccr}
\hline Meals (per week) & Controls & Unguided & Guided \\
\hline Breakfast & $6.4 \pm 0.3$ & $6.4 \pm 0.2$ & $6.2 \pm 0.3$ \\
Morning snack & $2.5 \pm 0.4$ & $3.2 \pm 0.4$ & $3.0 \pm 0.4$ \\
Lunch & $5.0 \pm 0.4$ & $4.8 \pm 0.5$ & $5.0 \pm 0.4$ \\
Afternoon snack & $2.6 \pm 0.4$ & $1.8 \pm 0.4$ & $2.7 \pm 0.4$ \\
Dinner & $6.6 \pm 0.1$ & $6.7 \pm 0.1$ & $6.6 \pm 0.2$ \\
Evening snack & $2.0 \pm 0.4$ & $1.8 \pm 0.3$ & $2.3 \pm 0.4$ \\
Evening meal & $4.5 \pm 0.4$ & $4.4 \pm 0.4$ & $5.2 \pm 0.3$ \\
Midnight snack & $0.5 \pm 0.2$ & $0.2 \pm 0.1$ & $0.2 \pm 0.1$ \\
\hline
\end{tabular}

Table IV. Daily intake of dairy products in controls, unguided and guided IBS (means \pm SEM).

\begin{tabular}{lccc}
\hline Dairy products $(\mathrm{g})$ & Controls & Unguided & Guided \\
\hline Milk products, whole fat & $53.0 \pm 30.4$ & $26.2 \pm 9.8$ & $20.3 \pm 7.7$ \\
Milk products, low-fat & $267.9 \pm 50.9$ & $72.8 \pm 18.9^{\mathrm{b}, \mathrm{f}}$ & $195.8 \pm 55.7$ \\
Sour milk with probiotic supplement ${ }^{\mathrm{a}}$ & $100.5 \pm 50.4$ & $64.2 \pm 19.7^{\mathrm{d}, \mathrm{f}}$ & $151.6 \pm 38.6^{\mathrm{c}, \mathrm{f}}$ \\
Yoghurt & $108.2 \pm 42.3$ & $60.9 \pm 15.7$ & $64.2 \pm 10.8$ \\
Soy, rice and oat milk & $1.2 \pm 1.0$ & $36.2 \pm 25.2$ & $12.6 \pm 7.1$ \\
Brown goat cheese & $4.8 \pm 2.1$ & $2.9 \pm 1.0$ & $3.6 \pm 1.2$ \\
Cheese, whole fat & $14.7 \pm 1.8$ & $17.0 \pm 3.0$ & $14.2 \pm 2.8$ \\
Cheese low fat & $4.2 \pm 1.8$ & $2.1 \pm 1.0$ & $2.4 \pm 0.8$ \\
Mold cheese & $0.94 \pm 0.3$ & $0.8 \pm 0.7^{\mathrm{b}, \mathrm{e}}$ & $0.3 \pm 0.1^{\mathrm{c}, \mathrm{f}}$ \\
\hline
\end{tabular}

'Includes the brand 'Tine Biola' containing LGG ${ }^{\circledR}$ (Lactobacillus rhamnosus GG), and the brand 'Tine Cultura' containing Lactobacillus acidophilus La-5 and Bifidobacterium Bb-12. ${ }^{\mathrm{b}}$ Controls vs. unguided IBS patients. ${ }^{\mathrm{c}}$ Controls vs. guided IBS patients. ${ }^{\mathrm{d}} \mathrm{Guided}$ IBS patients vs. unguided IBS patients. ${ }^{\mathrm{e}} \mathrm{P}<0.05 ;{ }^{\mathrm{f}} \mathrm{P}<0.01$.

MoBa FFQ. The FFQ showed that there was no statistical difference in the intake of calories, carbohydrates (total, starch and fiber), proteins, fat (total, saturated, cholesterol, trans, mono-unsaturated or polyunsaturated) or sugar between the guided patients, unguided patients and controls (Table II). Nor was there any statistically significant difference in the number of meals or meal pattern among the patient groups or between the patients and controls (Table III). There was a significant lower consumption of alcohol in both the guided and unguided IBS patients as compared to the controls (Table II). The consumption of beer and wine was $45.0 \pm 10.9$ and $34.2 \pm 5.9$ $\mathrm{ml}$ in the controls, $13.9 \pm 5.9$ and $14.5 \pm 4.3 \mathrm{ml}$ in the unguided patients and $21.0 \pm 6.5$ and $16 \pm 2.9 \mathrm{ml}$ in the guided patients, respectively, per day. There was a significantly lower consumption of beer and wine between the controls and the unguided IBS patients $(\mathrm{P}=0.0008$ and 0.0017 , respectively). Similarly, there was a significantly low consumption of beer and wine between the controls and guided IBS patients $(\mathrm{P}=0.0095$ and 0.0163 , respectively). There was no statistical difference in alcohol consumption or intake of beer/wine among the two IBS patient groups.

The difference in the intake of milk and milk products between the controls and IBS patients is summarized in Table IV. The calcium intake in the unguided IBS patients was significantly lower than the intake in the controls and guided patients $(\mathrm{P}=0.020$ and 0.033 , respectively). The results of intake of vegetables and fruit are provided in Table V, and of micronutrients and minerals in Table VI. The differences in wheat and wheat product consumption in the controls, unguided and guided IBS patients are shown in Table VII. The intake of rice, millet and couscous was $38.1 \pm 5.6,22.1 \pm 3.9$ and $34.5 \pm 4.9 \mathrm{~g} /$ day in the controls, unguided and guided IBS patients, respectively, which reflects a significantly lower consumption among unguided patients compared to both guided IBS patients $(\mathrm{P}=0.02)$ and controls $(\mathrm{P}=0.001)$.

$S F-N D I$. The reduction in the quality of life in the controls, unguided and guided IBS patients amounts to 10.9 \pm 0.3 . $31.6 \pm 1.6$ and $22.7 \pm 1.2$ (mean \pm SEM), respectively (Fig. 1A). The reduction in quality of life as assessed by the SF-NDI form was significantly lower in the guided than unguided IBS patients $(\mathrm{P}=0.0001)$. Both guided and unguided IBS patients had significantly lower quality of life than controls (both $\mathrm{P}<0.0001)$.

$I B S-Q O L$. The total score of quality of life as measured by the IBS-QOL questionnaire in unguided and guided IBS patients was $68.5 \pm 2$ and $75.4 \pm 2.1$ (mean \pm SEM). There was a significant improvement in the quality of life of guided IBS patients as compared to unguided ones $(\mathrm{P}=0.015)$ (Fig. 1B). 
Table V. Daily intake of various vegetables, fruits and berries in controls, unguided and guided IBS patients (means \pm SEM).

\begin{tabular}{|c|c|c|c|}
\hline Vegetable/fruits/berries (g) & Controls & Unguided & Guided \\
\hline Raw vegetables & $45.2 \pm 7.2$ & $18.9 \pm 3.2^{\mathrm{a}, \mathrm{f}}$ & $39.4 \pm 7.3$ \\
\hline Cauliflower, raw & $1.6 \pm 0.3$ & $1.8 \pm 0.5$ & $1.9 \pm 0.2$ \\
\hline Cauliflower, cooked & $7.6 \pm 1.1$ & $9.6 \pm 1.6$ & $10.3 \pm 1.6$ \\
\hline Broccoli, raw & $2.3 \pm 0.3$ & $2.6 \pm 0.9^{\mathrm{c}, \mathrm{e}}$ & $5.4 \pm 1.1^{\mathrm{b}, \mathrm{d}}$ \\
\hline Broccoli, cooked & $8.2 \pm 1.2$ & $6.2 \pm 1.1$ & $8.8 \pm 1.3$ \\
\hline Peas & $2.9 \pm 0.2$ & $7.3 \pm 2.7$ & $4.6 \pm 1.2$ \\
\hline Cabbage, raw & $1.8 \pm 0.2$ & $1.5 \pm 0.1$ & $4.2 \pm 1.8$ \\
\hline Cabbage, cooked & $2.5 \pm 0.2$ & $4.9 \pm 2.0$ & $4.7 \pm 1.9$ \\
\hline Paprika, raw & $9.9 \pm 1.5$ & $4.7 \pm 0.9^{\mathrm{a}, \mathrm{e}}$ & $7.9 \pm 2.2^{\mathrm{b}, \mathrm{d}}$ \\
\hline Paprika, cooked & $3.2 \pm 0.6$ & $3.5 \pm 0.7$ & $3.2 \pm 0.6$ \\
\hline Onion, leak, garlic & $12.6 \pm 1.8$ & $7.5 \pm 1.2^{\mathrm{a}, \mathrm{d}}$ & $7.9 \pm 1.8^{\mathrm{b}, \mathrm{e}}$ \\
\hline Tomatoes & $78.8 \pm 8.6$ & $38.1 \pm 4.5^{\mathrm{a}, \mathrm{f}}$ & $59.0 \pm 7.1$ \\
\hline Potatoes, fried & $4.6 \pm 0.7$ & $8.0 \pm 1.0^{\mathrm{a}, \mathrm{d}}$ & $6.6 \pm 0.9$ \\
\hline Potatoes, cooked, mashed or gratinated & $34.4 \pm 3.9$ & $51.1 \pm 6.1^{\mathrm{a}, \mathrm{d}}$ & $58.8 \pm 5.8^{\mathrm{b}, \mathrm{e}}$ \\
\hline Orange & $43.8 \pm 11.7$ & $50.4 \pm 10.9$ & $88.2 \pm 17.1$ \\
\hline Banana & $37.1 \pm 4.7$ & $35.0 \pm 6.9$ & $51.2 \pm 13.0$ \\
\hline Grapes & $12.0 \pm 1.8$ & $22.5 \pm 7.5$ & $20.1 \pm 5.4$ \\
\hline Pears & $19.0 \pm 3.8$ & $34.4 \pm 9.9$ & $16.9 \pm 4.2$ \\
\hline Apple & $66.3 \pm 11.0$ & $50.8 \pm 13.3$ & $54.9 \pm 7.1$ \\
\hline Peach & $14.7 \pm 3.4$ & $23.3 \pm 14.3$ & $15.9 \pm 4.2$ \\
\hline Grapefruit & $3.9 \pm 1.1$ & $3.0 \pm 0.5$ & $10.0 \pm 6.1$ \\
\hline Kiwi & $12.9 \pm 6.7$ & $13.7 \pm 4.5$ & $14.2 \pm 3.2$ \\
\hline Mango & $4.8 \pm 0.8$ & $5.5 \pm 1.5$ & $4.8 \pm 0.8$ \\
\hline Plums & $4.8 \pm 1.0$ & $6.7 \pm 2.2$ & $6.0 \pm 1.3$ \\
\hline Melon & $8.1 \pm 1.3$ & $14.2 \pm 4.1$ & $8.2 \pm 0.9$ \\
\hline Blueberry & $12.0 \pm 2.7$ & $23.6 \pm 11.7$ & $14.5 \pm 3.1$ \\
\hline Strawberry & $13.2 \pm 3.4$ & $22.8 \pm 8.5$ & $14.1 \pm 4.9$ \\
\hline Prunes, dried & $1.7 \pm 0.4$ & $9.8 \pm 7.9$ & $3.5 \pm 1.1$ \\
\hline Apricot, dried & $2.3 \pm 0.5$ & $6.8 \pm 3.5$ & $6.2 \pm 2.7$ \\
\hline Mushrooms & $5.8 \pm 1.0$ & $3.2 \pm 0.9^{\mathrm{a}, \mathrm{e}}$ & $5.9 \pm 1.6$ \\
\hline Green beans & $1.7 \pm 0.3$ & $0.7 \pm 0.3^{\mathrm{a}, \mathrm{d}}$ & $0.9 \pm 0.2$ \\
\hline
\end{tabular}

${ }^{\mathrm{a} C}$ Controls vs. unguided IBS patients. ${ }^{\mathrm{b}}$ Controls vs. guided IBS patients. ${ }^{\mathrm{c}}$ Guided IBS patients vs. unguided IBS patients. ${ }^{\mathrm{d}} \mathrm{P}<0.05 ;{ }^{\mathrm{e}} \mathrm{P}<0.01 ;{ }^{\mathrm{f}} \mathrm{P}<0.001$.

All the domains were significantly improved in the guided IBS patients, except health worry, food avoidance and sexual function (Table VIII).

Birmingham IBS symptom questionnaire. The total score of symptoms as assessed by the Birmingham IBS symptom questionnaire was lower, but not significantly reduced in the guided IBS patients compared to the unguided patients (Fig. 2). Abdominal pain was significantly reduced in the guided IBS patients. There was no statistical difference between the unguided and guided IBS patients in regards to diarrhea and constipation.

\section{Discussion}

Although the majority of patients with IBS believe diet plays a significant role in their symptoms, dietary surveys among IBS patients in the community failed to detect any differences in dietary composition between IBS patients and community controls $(28,31)$. In the present study, there were no statistical differences in the intake of calories, carbohydrates, proteins and fats between IBS patients and controls. Nor was there any statistical difference in the number of meals or meal patterns among the IBS patients and controls. These findings are in agreement with the previously mentioned studies. More detailed assessment of the diet in IBS patients revealed, however, that IBS patients are selective in their choice of food.

The present finding that IBS patients have a lower alcohol consumption than controls is in accordance with earlier observations that IBS patients reported intolerance to various alcoholic beverages; as many as $12 \%$ either limit or avoid such beverages $(28,40)$.

The most significant dietary source of calcium in the Western world is milk and other dairy products, and the calcium content of these food items contributes to $50-75 \%$ of the daily dietary intake (41). The common belief among IBS patients 
Table VI. Daily intake of vitamins and minerals in controls, unguided and guided IBS patients (means \pm SEM).

\begin{tabular}{|c|c|c|c|}
\hline & Controls & Unguided & Guided \\
\hline \multicolumn{4}{|l|}{ Vitamins } \\
\hline$\beta$-carotene (mg) & $3.6 \pm 0.5$ & $2.5 \pm 0.3^{\mathrm{a}, \mathrm{d}}$ & $3.9 \pm 0.5^{\mathrm{b}, \mathrm{d}}$ \\
\hline Folate $(\mu \mathrm{g})$ & $278.2 \pm 23.3$ & $257.3 \pm 17.8$ & $296.4 \pm 19.2$ \\
\hline Niacin equivalents $(\mu \mathrm{g})$ & $33.8 \pm 1.9$ & $30.1 \pm 1.3$ & $33.7 \pm 1.6$ \\
\hline Retinol equivalents (mg) & $1.3 \pm 0.1$ & $1.0 \pm 0.09^{\mathrm{a}, \mathrm{d}}$ & $1.2 \pm 0.09$ \\
\hline Riboflavin (mg) & $2.1 \pm 0.2$ & $1.6 \pm 0.1^{\mathrm{a}, \mathrm{d}}$ & $1.9 \pm 0.1^{\mathrm{b}, \mathrm{d}}$ \\
\hline Thiamin (mg) & $1.6 \pm 0.1$ & $1.3 \pm 0.08$ & $1.5 \pm 0.1$ \\
\hline Vitamin $\mathrm{B}_{6}(\mathrm{mg})$ & $1.6 \pm 0.1$ & $1.4 \pm 0.07$ & $1.7 \pm 0.1^{\mathrm{b}, \mathrm{d}}$ \\
\hline Vitamin $\mathrm{B}_{12}(\mu \mathrm{g})$ & $6.3 \pm 0.5$ & $5.6 \pm 0.4$ & $6.3 \pm 0.5$ \\
\hline Vitamin C (mg) & $128 \pm 11.9$ & $134.9 \pm 14.7$ & $167.7 \pm 18.0$ \\
\hline Vitamin $\mathrm{D}(\mu \mathrm{g})$ & $3.9 \pm 0.3$ & $3.8 \pm 0.3$ & $3.8 \pm 0.3$ \\
\hline Vitamin E (mg) & $12.0 \pm 1.0$ & $12.3 \pm 1.3$ & $12.5 \pm 0.9$ \\
\hline \multicolumn{4}{|l|}{ Minerals } \\
\hline Calcium (mg) & $1,184.3 \pm 126.6$ & $825.8 \pm 65.1^{\mathrm{a}, \mathrm{d}}$ & $1,065.1 \pm 82.3^{\mathrm{b}, \mathrm{d}}$ \\
\hline Cupper (mg) & $1.5 \pm 0.09$ & $1.3 \pm 0.09$ & $1.5 \pm 0.08$ \\
\hline Iron (mg) & $12.0 \pm 0.8$ & $10.8 \pm 0.6$ & $11.0 \pm 0.6$ \\
\hline Magnesium (mg) & $449.3 \pm 29.2$ & $373.2 \pm 22.2^{\mathrm{a}, \mathrm{d}}$ & $433.1 \pm 26.8$ \\
\hline Phosphorus (mg) & $1,890.2 \pm 133.7$ & $1,490 \pm 81 \cdot 1^{\mathrm{a}, \mathrm{d}}$ & $1,768.4 \pm 103.6$ \\
\hline Potassium (mg) & $4,259.7 \pm 268.6$ & $3,632.6 \pm 225.3$ & $4,355.7 \pm 271.3$ \\
\hline Selenium $(\mu \mathrm{g})$ & $60.8 \pm 3.6$ & $54.6 \pm 2.7$ & $61.3 \pm 3.1$ \\
\hline Sodium (mg) & $2,988.5 \pm 162.7$ & $2,799.8 \pm 152.1$ & $2,866.4 \pm 139.4$ \\
\hline Zink (mg) & $12.3 \pm 0.8$ & $11.4 \pm 0.6$ & $10.4 \pm 0.5$ \\
\hline
\end{tabular}

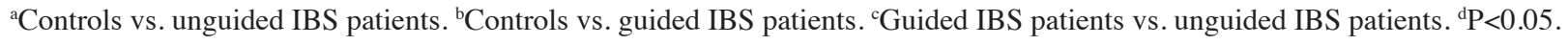

Table VII. Daily intake of wheat and wheat products in controls, unguided and guided IBS patients (means \pm SEM).

\begin{tabular}{lccc}
\hline Measured in grams $(\mathrm{g})$ & Controls & Treated & Untreated \\
\hline White bread & $63.7 \pm 13.5$ & $72.3 \pm 12.5$ & $97.1 \pm 20.0$ \\
Dark bread & $105.1 \pm 17.8$ & $73.1 \pm 12.9$ & $71.1 \pm 17.6$ \\
Spaghetti, pasta & $29.1 \pm 4.4$ & $17.8 \pm 3.1^{\mathrm{b}, \mathrm{e}}$ & $18.9 \pm 3.7^{\mathrm{a}, \mathrm{e}}$ \\
Waffles, pancakes & $8.4 \pm 1.0$ & $10.0 \pm 1.6$ & $8.1 \pm 1.2$ \\
Cakes & $7.5 \pm 1.1$ & $8.7 \pm 1.4$ & $6.5 \pm 0.8$ \\
Crisp bread & $16.5 \pm 3.5$ & $17.6 \pm 4.7$ & $16.1 \pm 3.5$ \\
Buns & $5.7 \pm 1.2$ & $3.8 \pm 1.2^{\mathrm{b}, \mathrm{e}}$ & $3.3 \pm 0.6^{\mathrm{a}, \mathrm{d}}$ \\
\hline
\end{tabular}

${ }^{\mathrm{a} C}$ Controls vs. unguided IBS patients. ${ }^{\mathrm{b}}$ Controls vs. guided IBS patients. ${ }^{\mathrm{c}}$ Guided IBS patients vs. unguided IBS patients. ${ }^{\mathrm{d}} \mathrm{P}<0.05 ;{ }^{\mathrm{e}} \mathrm{P}<0.01 ;{ }^{\mathrm{f}} \mathrm{P}<0.001$.

is that lactose is the main cause of their symptoms (42). This may be the cause for the lower consumption of milk and milk products found among the unguided IBS patients in this study, which in turn explains the observation made here of a lower intake of calcium in these patients. IBS patients that did not receive guidance on diet management consumed only one third of the milk and milk products compared to the controls. They had, however, a much higher consumption of alternative milk products, such as soy, rice and oat milk, compared to the IBS patients that received guidance on diet management (3 times as much) and controls (30 times as much). This appears to be the result of a conscious choice to replace lactose-containing food items in their diet. However, despite such replacement, IBS patients still had a significantly lower intake of calcium than IBS patients that received guidance on diet management and controls (826, 1,065 and 1,185 mg/day, respectively). This is in accordance with the recommendations $(800 \mathrm{mg} /$ day $)$ for the age group of 20-60 years, while it is $900 \mathrm{mg} / \mathrm{day}$ for those between 18 and 20 years. These patients are at risk of not meeting their daily calcium needs. Milk and milk products are also abundant in phosphorus and contribute $20-30 \%$ of the daily phosphorus intake (41). The reduced consumption of these food items is most likely the cause of the significantly lower intake in phosphorus when comparing IBS patients to controls. Unguided IBS patients also had a significantly lower intake of the vitamin riboflavin, as milk counts for an average of $25-30 \%$ of the riboflavin in a Western diet (41). This may explain such deviation from the control group values. 
Table VIII. Scores of the 8 domains of the IBS quality of life questionnaire in unguided and guided IBS patients (means \pm SEM).

\begin{tabular}{lccc}
\hline & Unguided & Guided & P-values \\
\hline Dysphoria & $65.3 \pm 2.7$ & $77.8 \pm 2.2$ & $0.0009^{\mathrm{c}}$ \\
Interference with activity & $70.2 \pm 2.5$ & $78.5 \pm 2.1$ & $0.0070^{\mathrm{b}}$ \\
Body image & $60.3 \pm 2.2$ & $70.3 \pm 2.5$ & $0.0020^{\mathrm{b}}$ \\
Health worry & $73.3 \pm 2.4$ & $78.5 \pm 2.3$ & 0.0930 \\
Food avoidance & $59.4 \pm 3.3$ & $59.4 \pm 2.6$ & 0.9920 \\
Social reactions & $73.4 \pm 2.5$ & $83.8 \pm 2.3$ & $0.0035^{\mathrm{b}}$ \\
Sexual relations & $75.6 \pm 3.4$ & $81.0 \pm 3.2$ & 0.1156 \\
Impact on relations & $73.3 \pm 2.9$ & $81.0 \pm 2.1$ & $0.0352^{\mathrm{a}}$
\end{tabular}

${ }^{\mathrm{a}} \mathrm{P}<0.05 ;{ }^{\mathrm{b}} \mathrm{P}<0.01 ;{ }^{\mathrm{c}} \mathrm{P}<0.001$.

A

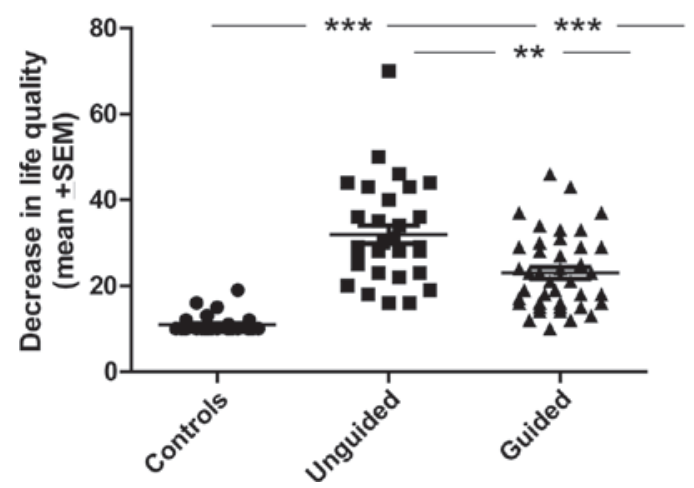

B

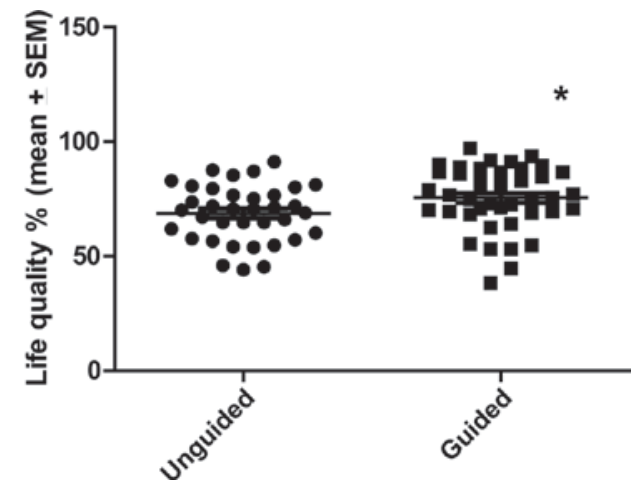

Figure 1. Total score of quality of life of controls, unguided and guided IBS patients as assessed by (A) the SF-NDI quality of life questionnaire and (B) the IBS-QOL questionnaire. ${ }^{*} \mathrm{P}<0.05 ;{ }^{* *} \mathrm{P}<0.01 ;{ }^{* * *} \mathrm{P}<0.001$.

A

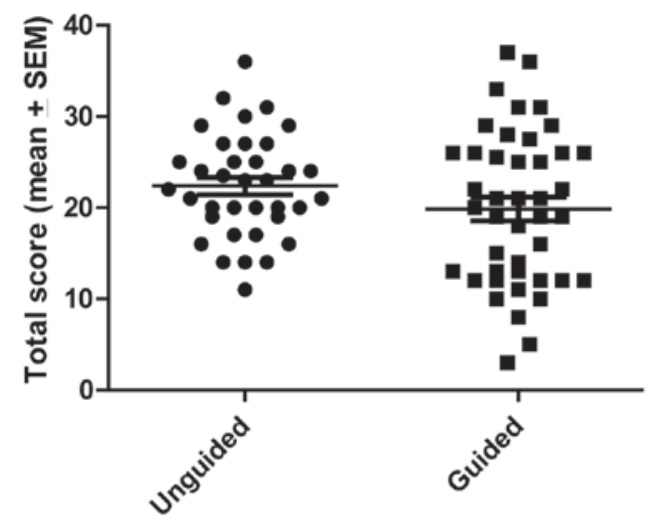

C

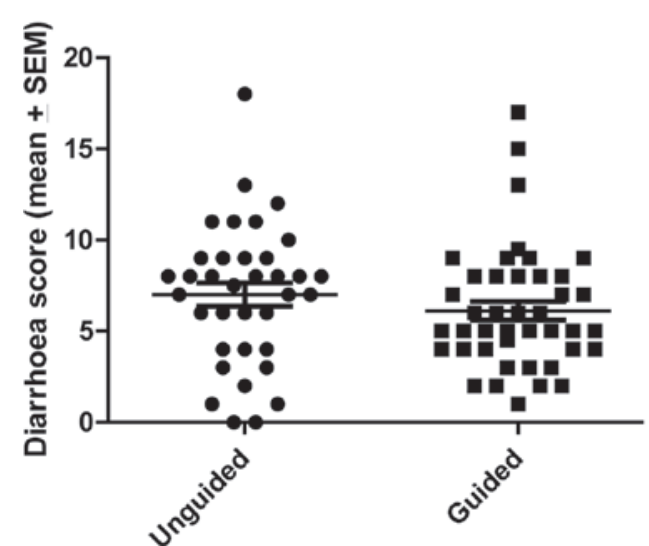

B

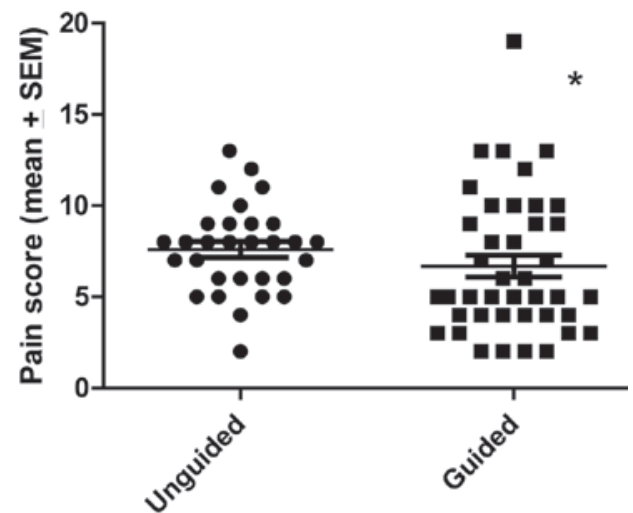

D

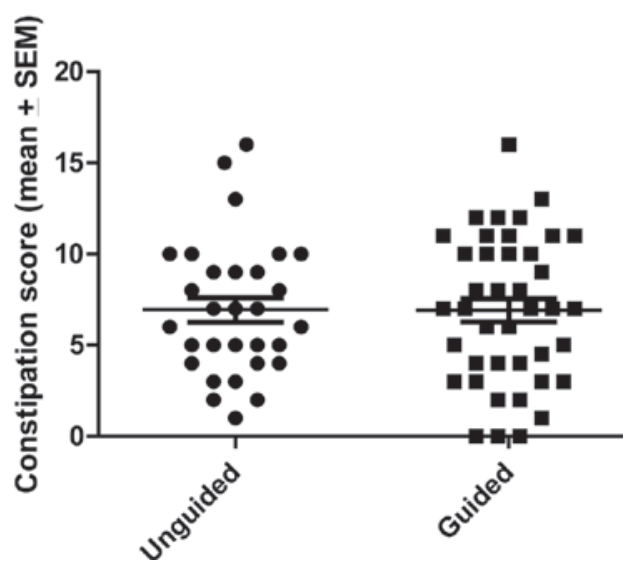

Figure 2. Total score and the three dimensions of the Birmingham IBS Symptom score questionnaire in unguided and guided IBS patients. "P<0.05. 
Unfortunately, the MoBa FFQ does not make it possible to obtain the exact information of a patient's consumption of spelt-containing food items. A number of patients had, however, added spelt products based on a question asking for additional food items not asked for in the questionnaire. In clinical practice, IBS patients that received guidance on diet management reported using spelt products, such as bread and pasta, instead of wheat products. What the IBS patients reported was a significantly lower consumption of spaghetti, pasta, rice, millet, couscous and buns compared to the controls. Spaghetti, pasta and couscous are products made using durum wheat, which tend to be high in FODMAPs, while rice tends to be low (43). The consumption of spaghetti, pasta and buns was lower in both the unguided and guided IBS patients. In addition to a significantly lower intake of spaghetti and pasta, the unguided patients also reported a significantly lower consumption of rice, millet, couscous and buns compared to the controls and guided IBS patients. Moreover, there was a significantly lower intake of green beans and mushrooms in unguided IBS patients compared to the controls. This may have caused an improvement of symptoms after the self-administered change in diet, which resulted in the limitation or exclusion of foods from the daily intake (40).

The significantly lower consumption of certain raw vegetables (raw broccoli, paprika, onion, leaks, garlic, tomatoes, mushrooms and green beans) is most likely the reason for the significantly lower intake of retinol equivalent, $\beta$-carotene and magnesium in the unguided IBS patients compared to the controls. Although not significant, a lower consumption was also reported for cabbage, raw broccoli and cooked potatoes. The total vitamin A content of foods is expressed as $\mu \mathrm{g}$ retinol equivalents, which is the sum of what is provided by retinols and from carotenoids. There was no significant difference in the intake of retinol. The difference in the intake of $\beta$-carotene was most likely due to the significant difference in retinol equivalent intake among the groups. The lower intake of paprika, broccoli and tomatoes (foods rich in $\beta$-carotene) may explain these results.

Magnesium is found abundantly in legumes (beans and peas), nuts and seeds, and whole unrefined grains. The reported lower consumption of beans and dark bread in the unguided IBS patients compared to the controls may have been the cause of this significant difference in magnesium intake. Although there was no statistical difference found when comparing the consumption of white and dark bread in IBS patients and controls, there was a marked difference in the amount consumed. Both the unguided and guided IBS patients reported a lower consumption of dark bread compared to the controls. On the other hand, the unguided IBS patients had a considerable higher intake of white bread in their daily diet. There was a significantly lower intake of vitamin $B_{6}$ in the unguided IBS patients comparing their intake to guided IBS patients. Food items, such as bananas, beans, milk and vegetables, are rich in vitamin $B_{6}$ and the present finding of a decrease in the consumption of these items by the unguided IBS patients may explain this difference.

The unguided IBS patients reported a higher consumption of grapes, pears, peach, peas, mango, plums and melon compared to guided IBS patients and controls. These are all fruits and vegetables that are rich in FODMAPs and docu- mented as causal symptom factors. It is noteworthy that the advice provided at Stord Hospital is that these fruits are 'safe' as long as one peels the fruit (the peel contain most of the fructans). Although not significantly different, the consumption of dried prunes and apricots was higher in the IBS patients compared to the controls, and also among patient groups (unguided higher than guided patients). This could be attributed to the laxative effect on patients with IBS-C.

The guided IBS patients reported a consumption of sour milk products containing probiotics almost twice as often as the unguided IBS patients and one and a half times that of the controls. The products used were supplemented with Lactobacillus rhamnosus GG, Lactobacillus acidophilus La-5 and Bifidobacterium Bb-12. Patients with IBS were found to have fewer Lactobacillus spp. and Bifdobacterium $s p p$. in their intestinal flora than healthy individuals (44). These bacteria have been shown to bind to epithelial cells and inhibit pathogen binding, and to enhance barrier function (46). Furthermore, these bacteria do not produce gas on fermenting carbohydrates, an effect which would be amplified as they also inhibit Clostridia spp. (46). A number of studies have shown an improvement in flatulence and abdominal distension with a reduction in the composite IBS symptom score, following probiotic intake $(45,46)$. The increase in consumption of sour milk products containing probiotics by guided IBS patients may increase their tolerance to FODMAPs.

The present study showed that both the unguided and guided IBS patients had a reduced quality of life compared to the healthy controls as assessed by SF-NDI, which is in accordance with previous reports $(17,18,20)$. This reduction in quality of life was less in guided IBS patients. Furthermore, the IBS-QOL showed that the quality of life was significantly higher in the guided IBS patients than that in the unguided patients. These included the majority of the questionnaire domains. Although the total score and all of the dimensions evaluated using the Birmingham IBS symptom questionnaire were improved in the guided IBS patients compared to the unguided ones, only pain was statistically significant. One cannot exclude a statistical error type 1 ( $\alpha$ error).

In conclusion, IBS patients make a conscious choice to avoid certain food items, some of which belong to the FODMAP group. They, however, had a high consumption of other food items, which were rich in FODMAPs. They also avoided food sources important to their health. IBS patients, 2 years after receiving $2 \mathrm{~h}$ of guidance on diet management had a different dietary profile. They had a lower consumption of FODMAP-rich food, consumed more food with probiotic supplements and avoided less food sources that were important to their health. In addition, the quality of life was improved and IBS symptoms were reduced.

\section{Acknowledgements}

The authors wish to thank Professor Helle Margrethe Meltzer at the Norwegian Institute of Public Health, for her permission to use the FFQ questionnaire and for helping to process the data. They would like to express gratitude to Professor Hans Olav Fadnes, Head of the Department of Medicine, Stord Helse-Fonna Hospital, for his support. This study was supported by a grant from Helse-Fonna. 


\section{References}

1. Thompson WG: A world view of IBS. In: Irritable Bowe Syndrome: Diagnosis and Treatment. Camilleri M and Spiller R (eds.). Saunders, Philadelphia and London, pp17-26, 2002.

2. Agreus L, Svarsudd K, Nygren O and Tibblin G: Irritable bowel syndrome and dyspepsia in general population: overlap and lack of stability over time. Gastroenterology 109: 671-680, 1995.

3. Thompson WG and Heaton KW: Functional bowel disorders in apparently healthy people. Gastorenterology 79: 283-288, 1980.

4. Kennedy TM, Jones RH, Hungin AP, O'Flanagan H and Kelly P: Irritable bowel syndrome, gastro-oesophageal reflux, and bronchial hyper-responsiveness in the general population. Gut 43: 770-774, 1998.

5. Drossman DA, Li Z, Andruzzi E, et al: U.S. householder survey of functional gastrointestinal disorders. Prevalence, sociodemography, and health impact. Dig Dis Sci 38: 1569-1580, 1993.

6. Talley NJ, Gabriel SE, Harmsen WS, Zinsmeister AR and Evans RW: Medical costs in community subjects with irritable bowel syndrome. Gastroenterology 109: 1736-1741, 1995.

7. Hugin AP, Whonwell PJ, Tack J and Mearin F: The prevalence, patterns and impact of irritable bowel syndrome: an international survey of 40,000 subjects. Alment Pharmacol Ther 17: 643-650, 2003.

8. Jones R and Lydeard S: Irritable bowel syndrome in the general population. BMJ 304: 87-90, 1992.

9. Bordie AK: Functional disorders of the colon. J Indian Med Assoc 58: 451-456, 1972.

10. O'Keefe EA, Talley NJ, Zinsmeister AR and Jacobsen SJ: Bowel disorders impair functional status and quality of life in the elderly: a population-based study. J Biol Sci Med Sci 50: M184-M189, 1995.

11. Everhart JE and Renault PF: Irritable bowel syndrome in officebased practice in the United States. Gastroenterology 100 998-1005, 1991.

12. Wilson S, Roberts L, Roalfe A, Bridge P and Sukhdev S: Prevalence of irritable bowel syndrome: a community survey. Br J Gen Pract 54: 495-502, 2004.

13. Harvey RF, Salih SY and Read AE: Organic and functional disorders in 2000 gastroenterology outpatients. Lancet 1: 632-634, 1983.

14. Spiegel BM: The burden of IBS: looking at metrics. Curr Gastroenterol Rep 11: 265-269, 2009.

15. Systematic review on the management of irritable bowel syndrome in the European Union. Eur J Gastroenterol Hepatol 19 (Suppl 1): 11-37, 2007

16. Vandvik PO, Lydersen S and Farup PG: Prevalence, comorbidity and impact of irritable bowel syndrome in Norway. Scand J Gastroenterol 41: 650-656, 2006.

17. Li FX, Patten SB, Hilsden RJ and Sutherland LR: Irritable bowel syndrome and health-related quality of life: a population-based study in Calgary, Alberta. Can J Gastroenterol 17: 259-263, 2003.

18. Whitehead WE, Burnett CK, Cook EW III and Taub E: Impact of irritable bowel syndrome on quality of life. Dig Dis Sci 41: 2248-2253, 1996.

19. Luscombe FA: Health-related quality of life and associated psychosocial factors in irritable bowel syndrome: a review. Qual Life Res 9: 161-176, 2000.

20. Frank L, Kleinman L, Rentz A, Ciesla G, Kim JJ and Zacker C: Health-related quality of life associated with irritable bowel syndrome: comparison with other chronic diseases. Clin Ther 24 675-689, 2002.

21. Thompson WG, Heaton KW, Smyth GT and Smyth C: Irritable bowel syndrome in general practice: prevalence, characteristics, and referral. Gut 46: 78-82, 2000.

22. Martin R, Barron JJ and Zacker C: Irritable bowel syndrome: toward a cost-effective management approach. Am J Manag Care 7 (Suppl 8): 268-275, 2001.

23. Thompson WG, Longstreth GF, Drossman DA, Heaton KW, Irvine EJ and Muller-Lissner SA: Functional bowel disorders and functional abdominal pain. Gut 45 (Suppl 2): 43-47, 1999.

24. Hahn BA, Yan S and Strassels S: Impact of irritable bowel syndrome on quality of life and resource use in the United States and United Kingdom. Digestion 60: 77-81, 1999.
25. The Burden of Gastrointestinal Diseases. American Gastroenterological Association, Bethesda, MD, pp1-89, 2001.

26. Heizer WD, Southern S and McGovern S: The role of diet in symptoms of irritable bowel syndrome in adults: a narrative review. J Am Diet Assoc 109: 1204-1214, 2009.

27. Austin GL, Dalton CB, Hu Y, et al: A very low-carbohydrate diet improves symptoms and quality of life in diarrhoea-predominant irritable bowel syndrome. Clin Gastroenterol Hepatol 7: 706-708, 2009.

28. Simren M, Mansson A, Langkilde AM, Svedlund J, Abrahamsson H, Bengtsson U and Björnsson ES: Food-related gastrointestinal symptoms in the irritable bowel syndrome. Digestion 63: 108-115, 2001.

29. Nanda R, James R, Smith H, Dudley CR and Jewell DP: Food intolerance and irritable bowel syndrome. Gut 30: 1099-1104, 1989.

30. Jarret M, Heitkemper MM, Bond EF and Georges J: Comparsion of diet composition in women with and without functional bowel disorder. Gastroenterol Nurs 16: 253-258, 1994.

31. Saito YA, Locke GR III, Weaver A, Zinsmeister AR and Talley NJ: Diet and functional gastrointestinal disorders: a population-based case control study. Am J Gastroenterol 100: 2743-2748, 2005

32. Scherer SH and Samson HA: Food allergy: recent advances in pathophysiology and treatment. Annu Rev Med 60: 261-277, 2009.

33. Masson LF, McNeill G, Tomany JO, et al: Statistical approaches for assessing the relative validity of a food-frequency questionnaire: use of correlation coefficients and the kappa statistic. Public Health Nutr 6: 313-321, 2003.

34. Brantsaeter AL, Haugen M, Alexander J and Meltzer HM: Validity of a new food frequency questionnaire for pregnant women in the Norwegian Mother and Child Cohort Study (MoBa). Matern Child Nutr 4: 28-43, 2008.

35. Talley NJ, Verlinden M and Jones M: Quality of life in functional dyspepsia: responsiveness of the Nepean Dyspepsia Index and development of a new 10-item short form. Aliment Pharmacol Ther 15: 207-216, 2001.

36. Arslan G, Lind R, Olafsson S, Florvaag E and Berstad A: Quality of life in patients with subjective food hypersensitivity: applicability of the 10-item short form of the Nepean Dyspepsia Index. Dig Dis Sci 49: 680-687, 2004.

37. Patrick DL, Drossman DA, Frederick IO, DiCesare J and Puder KL: Quality of life in persons with irritable bowel syndrome: development and validation of a new measure. Dig Dis Sci 43: 400-411, 1998.

38. Drossman DA, Patrick DL, Whitehead WE, et al: Further validation of the IBS-QOL: a disease-specific quality-of-life questionnaire. Am J Gastroenterol 95: 999-1007, 2000.

39. Roalfe AK, Roberts LM and Wilson S: Evaluation of the Birmingham IBS symptom questionnaire. BMC Gastroenterol 8: 30-36, 2008.

40. Monsbakken KW, Vandvik PO and Farup PG: Perceived food intolerance in subjects with irritable bowel syndrome - etiology, prevalence and consequences. Eur J Clin Nutr 60: 667-672, 2006.

41. Geissler C: Human Nutrition. 11th edition. Elsevier Churchill, Livingstone, 2005.

42. Vesa TH, Seppo LM, Marteau PR, Sahi T and Korpela R: Role of irritable bowel syndrome in subjective lactose intolerance. Am J Clin Nutr 67: 710-715, 1998.

43. Biesiekierski JR, Rosella O, Rose R, et al: Quantification of fructans, galacto-oligosacharides and other short-chain carbohydrates in processed grains and cereals. J Hum Nutr Diet 24: 154-176, 2011.

44. Kassinen A, Krogius-Kurikka L, Mäkivuokko H, et al: The fecal microbiota of irritable bowel syndrome patients differs significantly from that of healthy subjects. Gastroenterology 133 : 24-33, 2007.

45. Brenner DM, Moeller MJ, Chey WD and Schoenfeld PS: The utility of probiotics in the treatment of irritable bowel syndrome: a systematic review. Am J Gastroenterol 104: 1033-1049, 2009.

46. Speller R: Review article: probiotics and prebiotics in irritable bowel syndrome. Alment Pharmacol Ther 28: 385-396, 2008. 